\title{
Greenland precipitation estimates from the atmospheric moisture budget
}

\author{
Frank M. Robasky and David H. Bromwich \\ Byrd Polar Research Center, The Ohio State University, Columbus
}

\begin{abstract}
Eight radiosonde stations surrounding Greenland at an average separation of $750 \mathrm{~km}$ are used to compute the atmospheric moisture budget. Radiosonde data were available from 1963-89, but were not used for 1963-79 due to insufficient data coverage which likely resulted in a major underestimation of large moisture inflow events. There is a mean annual inflow of moisture to the atmospheric volume over Greenland through its southeast and southwest sectors, and outflow to the northeast. Moisture convergences, equivalent to precipitation minus evaporation, yield an areal average of $32 \mathrm{~cm} \mathrm{yr}^{-1}$ of water equivalent; they also show high interand intra- annual agreement with earlier modeled precipitation estimates found by the authors and serve as further confirmation of their modeling results. The timeaveraged eddy component accounts for $90 \%$ of the total moisture convergence, reflecting the dominant contribution of precipitation from synoptic-scale cyclones.
\end{abstract}

\section{Introduction}

New deep ice cores from Greenland (i.e., those of the Greenland Ice Sheet Project II, or GISP2, and the Greenland Ice Core Project, or GRIP) reveal large changes in accumulation, oxygen isotope ratios, and dust concentrations over years to decades during the last glacial period in marked contrast to the "much less variable" Holocene [Alley et al., 1993; Johnsen et al., 1992; Taylor et al., 1993]. Fundamental to understanding these results is an appreciation of the large temporal snowfall variations that occur presently and why these take place. Understanding recent precipitation variations is also relevant to the question of global sea level change, as the Greenland Ice Sheet contains the global sea level equivalent of roughly $6 \mathrm{~m}$ and the mean annual precipitation amount over the ice sheet is equivalent to $1.4 \mathrm{~mm} \mathrm{yr}^{-1}$ of sea level decrease. At present interannual variations of areally-averaged precipitation over the polar ice sheets can only be found by indirect methods. Direct precipitation determinations are inaccurate due to problems inherent in the measurement of snowfall [Sevruk, 1993]; by contrast, glaciological accumulation measurements (via ice cores or snow pits) are reliable, but their limited spatial and temporal coverage restricts their application in this context to constructing approximate time mean distributions of accumulation (e.g., Ohmura and Reeh [1991]).

Satellite altimetry has been used to estimate changes in the surface elevation of the Greenland Ice Sheet south of $72^{\circ} \mathrm{N}$ [Zwally et al., 1989], but the results have been challenged (e.g., Van der Veen [1993]). Bromwich et al. [1993] modeled the precipitation falling over Greenland through parameterizing atmospheric vertical motion in terms of the advection of relative vorticity at the $500-\mathrm{hPa}$ level, tying this quantity to observed accumulation values at the summit of the Ice Sheet. This model successfully

Copyright 1994 by the American Geophysical Union.

Paper number 94GL01915

0094-8534/94/94GL-01915\$03.00 simulated the mean annual distribution of accumulation, and yielded a linear trend towards less precipitation amounting to $15 \%$ over the $1963-89$ period. The validity of this trend was supported by a number of lines of evidence, but no direct confirmation was possible due to the scarcity of Greenland precipitation/accumulation time series of sufficient quality.

Areally-averaged precipitation may also be inferred through computation of the atmospheric water vapor balance. In this framework, the precipitation falling out of a certain volume of the atmosphere minus the evaporation input from the surface is equal to the convergence of water vapor into this volume minus the time change of its water vapor content. This method has been applied at different locations and at various time and space scales (see Palmén [1967] for a review of early studies; also Alestalo [1983]; Bromwich [1988, 1990]; and Walsh and Zhou [1993]). Here, the atmospheric moisture budget method is applied to the Greenland Ice Sheet over a 10-year (1980-89) period. These results provide the best comparison data yet for judging the precipitation model results of Bromwich et al. [1993], and further illustrate the usefulness, and highlight some pitfalls, of atmospheric moisture budget calculations in the polar regions.

\section{Methods and Data}

The atmospheric water budget can be expressed as

$$
(\boldsymbol{P}-\bar{E}\rangle=-\langle\nabla \cdot \overline{\mathbf{Q}}\rangle-\left\langle\frac{\partial W}{\partial t}\right\rangle
$$

where the angle brackets represent spatial averaging, the overbars temporal averaging (monthly in this study), $\mathbf{P}$ precipitation, and $\mathbf{E}$ evaporation. $\mathbf{Q}$ represents the vertically-integrated horizontal moisture transport $(\mathrm{gV}$, where $q$ is specific humidity and $V$ is the horizontal wind vector) above a certain point on the Earth's surface, and $W$ is the vertically-integrated specific humidity (i.e., precipitable water). Equation (1) neglects the contribution of condensed water (as droplets or ice crystals), which is likely negligible in comparison to that of water vapor over periods of one month or more [Peixoto, 1973]. Similarly, for the monthly and annual periods considered here the second term on the right hand side of (1) was found to be very small in comparison to the flux divergence term $(\sim 1 \%)$, and was therefore ignored.

The time mean moisture flux may be expanded into the flux resulting from the time mean wind plus a transient eddy flux associated with the time covariance between the specific humidity and the wind. This is expressed as

$$
\bar{q} \nabla=\bar{q} \nabla+\overline{q^{\prime} V^{\prime}}
$$

Applying this formulation to (1) allows the moisture convergence resulting from the time mean wind and the transient eddies to be evaluated separately.

The basic data are temperature, dewpoint temperature, and wind speed and direction measured by twice-daily radiosonde launches from eight stations surrounding the Greenland Ice Sheet (Fig. 1). Individual soundings consist of data at both "mandatory" (i.e., surface, 1000 


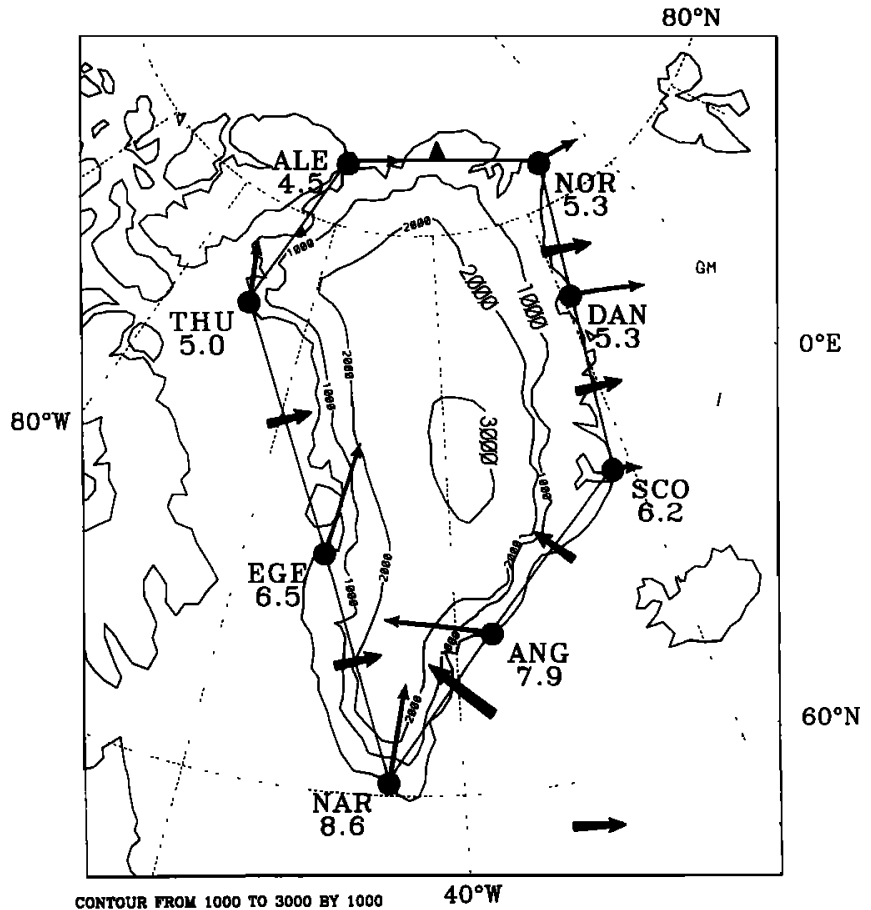

Figure 1. The stations providing radiosonde data: Narssarssuaq (NAR, station elevation $4 \mathrm{~m}$ ), Egedesminde (EGE, $27 \mathrm{~m}$ ), Thule (THU, $63 \mathrm{~m}$ ), Alert (ALE, $62 \mathrm{~m}$ ), Nord (NOR, $36 \mathrm{~m}$ ), Danmarkshavn (DAN, $14 \mathrm{~m}$ ), Scoresbysund (SCO, $65 \mathrm{~m}$ ), and Angmagssalik (ANG, 50 m). All are sponsored by Denmark except for Thule (USA) and Alert (Canada). Thin vectors represent mean annual transports over 1980-89 for each station; thick vectors are 1980-89 mean annual transports normal to each side of the Greenland polygon. The reference vector on the bottom right represents $10 \mathrm{~kg} \mathrm{~m}^{-1} \mathrm{~s}^{-1}$. Average annual precipitable water values (in $\mathrm{kg} \mathrm{m}^{-2}$ ) are below each station abbreviation. Elevation contours in 1000-m increments are given for Greenland.

$\mathrm{hPa}, 850 \mathrm{hPa}, 700 \mathrm{hPa}$, etc.) and "significant" (according to conventional vertical change criteria) pressure levels. Data were obtained for 1963-89 from the National Center for Atmospheric Research and the National Climatic Data Center. The period of usable data was shortened to 1973-89 when it became apparent that the 1963-72 data were severely deficient in significant level winds. The 1973-89 data were then subjected to an automated procedure to check for obviously erroneous observations. The errors were corrected if possible, sometimes through vertical or temporal interpolation, or else were deleted.

The individual soundings were then manipulated in several ways. Dewpoint temperatures for individual observations were converted to specific humidities based on saturation with respect to liquid water. The sounding data were then linearly interpolated in the vertical to 50 . $\mathrm{hPa}$ levels based on geopotential height, starting at the 1000-hPa level.

At each level of each sounding the horizontal moisture transport (i.e., qV) was calculated. Monthly mean soundings were constructed, and from these soundings monthly mean vertically-integrated transports (total, mean, and eddy) were computed via the trapezoidal rule. (Observation-by-observation departures from monthly means were averaged to yield monthly eddy quantities.) Moisture-related integrals were only carried out up to the $300-\mathrm{hPa}$ level, as atmospheric moisture decreases exponentially with height and at these high latitudes is negligible above this level. Data at a certain level must have been present for at least $1 / 3$ of the days of the month for that level to be considered sufficiently represented to be included in the vertical integration, and half of the vertical levels must have met this qualification for the integration to be performed. If vertical integration could not thus be performed for a particular month, vertically-integrated quantities from climatological monthly mean soundings were used. (These mean soundings were based only on 1980-89 data, for reasons to be explained below.) This climatological substitution was primarily needed for July through October 1981, for which no data from the Danish stations were available. Altogether, climatological substitutions were necessary for 26 out of a possible 1428 station-months.

Station Nord, on the northeastern coast of Greenland, ceased operation in April 1972. Therefore a simple scheme was devised, based on the relationship between mean transports at Nord and the nearest station (Danmarkshavn) for the $1 / 71-4 / 72$ period, to estimate monthly 1973-89 moisture transports for Nord based on known values at Danmarkshavn. The employment of a similar technique for a missing station in Antarctica was found to have an important beneficial impact on moisture convergence calculations over a segment of East Antarctica [Bromwich and Robasky, 1993], making the anomalous results for this area obtained by Connolley and King [1993] consistent with earlier findings.

The convergence of water vapor can be expressed, using the Gauss theorem, as

$$
\langle\nabla \bar{Q}\rangle=\frac{1}{A} \oint(\bar{Q} \cdot \boldsymbol{n}) d l
$$

where $\mathbf{A}$ is the area under consideration and $\mathbf{n}$ denotes the outward normal vector at any point on the boundary. This line integral was computed monthly around a polygon representing Greenland, with the eight upper-air stations as vertices (see Fig. 1). The mean station separation is $750 \mathrm{~km}$, and the area of the polygon is roughly $2.1 \times 10^{6} \mathrm{~km}^{2}$. The mean transport normal to each side of the polygon was computed as the normal component of the linear average of the transports at each end.

\section{Results}

Moisture convergences were calculated for each month, and the monthly convergences were summed to yield annual convergences. Evaporation over the majority of the Greenland Ice Sheet is likely small in comparison to precipitation (Ohmura and Reeh [1991] estimated a roughly $7 \%$ loss of mean annual precipitation due to evaporation over Greenland). Moisture convergence will therefore be used as a precipitation estimate for Greenland. Annual convergence values are plotted in Fig. 2 for 1973-89 along with areally-averaged precipitation over Greenland from the model of Bromwich et al. [1993]. The two estimates of precipitation show close agreement, in both magnitude and interannual variability, for the $1980-88$ period (and especially over 1982-88) but differ greatly for 1973-79. Furthermore, for some years during this early period the moisture budget calculations indicate a divergence of water vapor over Greenland. Preliminary investigation indicates that this discrepancy is due to an undersampling of larger moisture import events during the early part of this period. Total moisture transport at the two stations having the largest input of moisture to Greenland (Narssarssuaq and Angmagssalik, see Fig. 1) showed a trend towards higher values. These were not due to any sensor changes, but to a greater number of missing observations early in the period (Fig. 3). An examination of synoptic atmospheric analyses in the Greenland area for days of missing and non-missing radiosonde data revealed that missing radiosonde data 


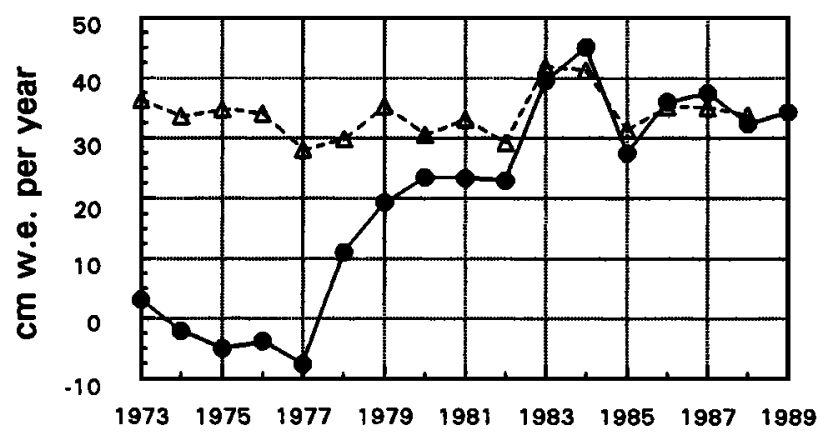

Figure 2. Time series of annual moisture convergences for 1973-89 (solid line with solid circles) and modeled precipitation (dashed line with triangles) for 1973-88 from Bromwich et al. [1993], both in cm per year of areally-averaged water equivalent.

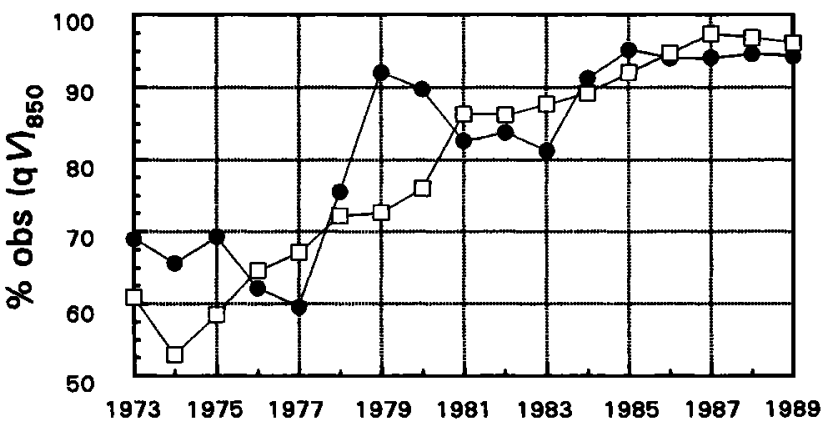

Figure 3. Time series of annual percentage of observations for which an $850-\mathrm{hPa}$ moisture transport calculation was possible. Circles: Angmagssalik. Squares: Narssarssuaq.

were more likely to occur during synoptic conditions favorable for large moisture transport into the southeast coast of Greenland. A similar strong bias against larger moisture transport events for several radiosonde stations in Antarctica was noted by Bromwich [1979].

Mean annual moisture transports for each station for 1980-89 are shown in Fig. 1, along with the mean annual values of precipitable water (W). These are in basic agreement with the analyses of Peixoto and Oort [1983]. The vertical profiles of the transports have also been examined [Robasky and Bromwich, 1994]. These indicate a deep layer of mid-level inflow (maximized at $600 \mathrm{hPa}$, or roughly $4 \mathrm{~km}$ ) for southwestern and western Greenland, with a mid- and low-level outflow in the northeast. The strong inflow across the southeast coast is maximized at a lower level, near $850 \mathrm{hPa}$ (roughly 1.3 $\mathrm{km}$ ). The large inflow of moisture over southern Greenland is consistent with the proximity of the Icelandic Low and North Atlantic storm track.

Annual convergences, including those due to the mean and eddy transports, for 1980-89 are shown in Fig. 4 along with the modeled precipitation from Bromwich $e t$ al. [1993]. Although the interannual variations of the total convergence more closely parallel the mean component, the eddy transports are responsible for nearly all of Greenland's moisture convergence. These eddy transports are associated with transient synoptic-scale storm systems. Figure 5 shows the seasonal cycle of mean monthly convergences and modeled precipitation over the 1980-89 period. Again, nearly all the precipitation is due to the eddy transports. There is a clear late summer maximum. The convergence results for September are questionable, however, in view of its anomalous mean divergence. The source of this discrepancy was traced to a relative September minimum in the usually large mean moisture inflow at Angmagssalik (Fig. 1), evident throughout the 1980-89

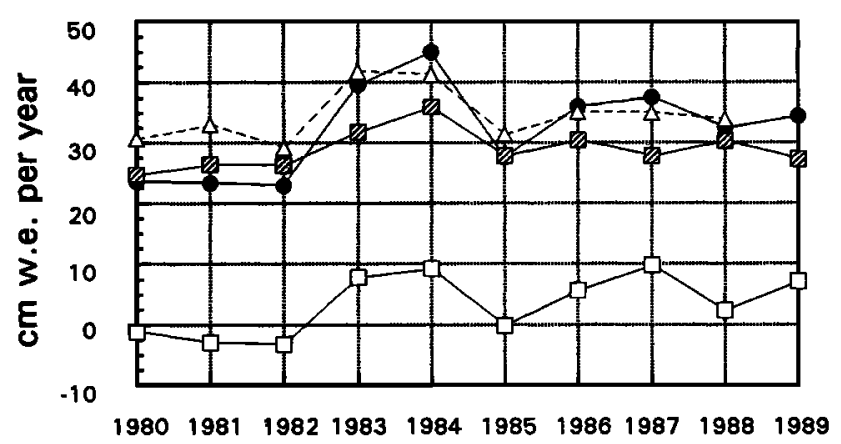

Figure 4. Time series of annual total moisture convergence (solid circles) with the mean (hollow squares) and eddy (hatched squares) components, and the modeled precipitation (hollow triangles joined by dashed lines). Units are $\mathrm{cm}$ per year of areally-averaged water equivalent.

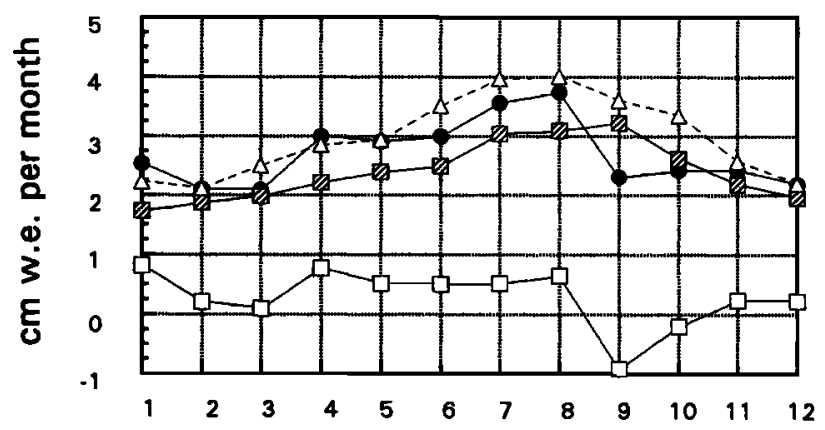

Figure 5. As in Fig. 4, but for average monthly values over 1980-89.

period. This local phenomenon requíres more study to determine its cause. The eddy convergences, however. show better correspondence to the modeled intra-annual cycle.

These moisture budget results, though limited to 198089 , are the best data available for comparisons with the precipitation model results of Bromwich et al. [1993]. The areally-averaged mean annual convergence over the 1980-89 period is $32.1 \mathrm{~cm}$ water equivalent (w.e.) $\mathrm{yr}^{-1}$ (34.3 cm w.e. $\mathrm{yr}^{-1}$ if evaporation is taken to be $7 \%$ of precipitation) compared to a mean annual modeled precipitation of $34.5 \mathrm{~cm}$ w.e. $\mathrm{yr}^{-1}$. These estimates are very close to the areally-averaged precipitation estimate of $34.0 \mathrm{~cm}^{\mathrm{w}}$.e. $\mathrm{yr}^{-1}$ derived from composited glaciological and meteorological observations by Ohmura and Reeh [1991]. Additionally, the time series of annual total convergence and modeled precipitation for 1980-89 (Fig. 4) show close correspondence. Thus a remarkably high level of agreement is found between these two independent estimates of Greenland precipitation.

\section{Conclusions}

The results of this study are further evidence that the moisture budget method of estimating precipitation can be reliably applied in the polar regions. However, the results also emphasize the critical need for understanding the biases which may result from missing data. In the present case, it is likely that the radiosonde observations at two crucial stations (at least) were biased against large moisture inflow events to such a large extent that a vast underestimate of convergence resulted.

Thus it appears, at least for Greenland, that adequate temporal sampling of the moisture transport events may be a more important data quality consideration than the commonly referred to difficulties in measuring atmospheric humidity at low air temperatures (e.g., 
Elliott and Gaffen [1991]). Several factors can be cited to explain this. First, while it is granted that moisture measurements for any one specific time may be inaccurate to some extent, usage of monthly mean soundings from a number of stations should allow for a certain amount of error cancellation. Second, moisture measurements at very low temperatures may not have a significant effect on moisture transport and convergence estimations because the major moisture transport events are associated with warm air advection in conjunction with synoptic scale storm systems, as was indicated by the dominance of the convergence due to the time-eddy transports. These warmer conditions would allow for more accurate moisture measurements. Conversely, the coldest temperatures are associated with exponentially smaller atmospheric moisture contents. In this study no attempt was made to correct for any systematic errors in moisture measurements, such as might occur between the Danish and non-Danish stations. These errors are likely to be small, as most of the stations are Danish, and the two non-Danish stations are located in the northern part of Greenland, where precipitable water and normal moisture transports are smallest (Fig. 1).

These moisture convergence results provide strong additional confirmation of the precipitation model results of Bromwich et al. [1993]. Although the key finding from that paper (a roughly $15 \%$ decrease in precipitation over 1963-89) could not be directly confirmed here, the magnitudes and interannual variability of the two methods matched very well over the available period, and discrepancies over 1973-79 were linked to a deficiency in the observational data. These two approaches to estimating precipitation are almost entirely computationally independent. Though both ultimately depend on the same radiosonde launches, the precipitation model was based primarily on the advection of relative vorticity calculated from $500-\mathrm{hPa}$ geopotential heights, while the moisture convergences are based on radiosonde-measured wind, moisture, and temperature. Consequently, the degree of agreement in the results is especially noteworthy. These results also confirm the conceptual approach of Bromwich et al. [1993]. The model was designed to attribute the majority of Greenland precipitation to transient synoptic-scale storm systems, and in the present results the convergence resulting from the eddy transports of moisture overwhelmingly dominates the total convergence.

Acknowledgments. This research was sponsored by the Climate and Global Change Program of the National Oceanic and Atmospheric Administration via grants NA90 AA-D-AC504 and NA36 GP0314 to D.H. Bromwich. Contribution 876 of the Byrd Polar Research Center.

\section{References}

Alestalo, M., The atmospheric water budget over Europe, in Variations in the Global Water Budget (A. StreetPerrott, M. Beran and R. Ratcliffe, eds.), pp. 67-79, D. Reidel, Hingham, Mass., 1983.

Alley, R.B., D.A. Meese, C.A. Shuman, A.J. Gow, K.C. Taylor, P.M. Grootes, J.W.C. White, M. Ram, E.D. Waddington, P.A. Mayewski, and G.A. Zielinski, Abrupt increase in Greenland snow accumulation at the end of the Younger Dryas event, Nature, 362, 527529, 1993.

Bromwich, D.H., Precipitation and accumulation estimates for East Antarctica, derived from rawinsonde information, Research Report, Department of Meteorology, University of Wisconsin, Madison, 142 pp, 1979.

Bromwich, D.H., Snowfall in high southern latitudes, $R e v$. Geophys., 26, 149-168, 1988.
Bromwich, D.H. Estimates of Antarctic precipitation, Nature, 343, 627-629, 1990.

Bromwich, D.H. and F.M. Robasky, Recent precipitation trends over the polar ice sheets, Meteorol. Atmos. Phys., 51, 259-274, 1993.

Bromwich, D.H., F.M. Robasky, R.A. Keen, and J.F. Bolzan, Modeled variations of precipitation over the Greenland Ice Sheet, J. Climate, 6, 1253-1268, 1993.

Connolley, W.M. and J.C. King, Atmospheric watervapour transport to Antarctica inferred from radiosondes, Quart. J. Roy. Meteor. Soc., 119, 325-342, 1993.

Elliott, W.P. and D.J. Gaffen, On the utility of radiosonde humidity archives for climate studies, $B$ ull. Amer. Meteor. Soc., 72, 1507-1520, 1991.

Johnsen, S.J., H.B. Clausen, W. Dansgaard, K. Fuhrer, N. Gundestrup, C.U. Hammer, P. Iversen, J. Jouzel, B. Stauffer, and J.P. Steffensen, Irregular glacial interstadials recorded in a new Greenland ice core, Nature, 359, 311-313, 1992.

Ohmura, A., and $\mathbf{N}$. Reeh, New precipitation and accumulation maps for Greenland, J. Glaciol., 37, 140$148,1991$.

Palmén, E., Evaluation of atmospheric moisture transport for hydrological purposes, Operational Hydrology Report 1 , World Meteorological Organization, Geneva, 1967.

Peixoto, J.P., Atmospheric vapour flux computations for hydrological purposes, Operational Hydrological Report 20, World Meteorological Organization, Geneva, 1973.

Peixoto, J.P. and A.H. Oort, The atmospheric branch of the hydrological cycle and climate, in Variations in the Global Water Budget (A. Street-Perrott, M. Beran and R. Ratcliffe, eds.), pp. 5-65, D. Reidel, Hingham, Mass., 1983.

Robasky, F.M. and D.H. Bromwich, Annual precipitation estimates for the Greenland Ice Sheet from the atmospheric moisture budget: Results and implications, Fifth Symposium on Global Change Studies, January 23-28, 1994, Nashville, Tennessee, preprint volume, pp. 156-159, American Meteorological Society, Boston, 1994.

Sevruk, B., Systematic error of precipitation measurements, GEWEX News, 3(2), 4-5, 1993.

Taylor, K.C., G.W. Lamorey, G.A. Doyle, R.B. Alley, P.M. Grootes, P.A. Mayewski, J.W.C. White, and L.K. Barlow, The "flickering switch" of late Pleistocene climate change, Nature, 361, 432-436, 1993.

Van der Veen, C.J., Interpretation of shortterm ice-sheet elevation changes inferred from satellite altimetry, Climatic Change, 23, 383-405, 1993.

Walsh, J.E. and X. Zhou, Estimation of Arctic precipitation from water vapor flux convergence, Fourth AMS Conference on Global Change Studies, January 17-22, 1993, Anaheim, California, preprint volume, pp. 324-328, American Meteorological Society, Boston, 1993.

Zwally, H.J., A.C. Brenner, J.A. Major, R.A. Bindschadler, and J.G. Marsh, Growth of Greenland Ice Sheet: Measurement, Science, 246, 1587-1589, 1989.

F.M. Robasky and David H. Bromwich, Byrd Polar Research Center, The Ohio State University, 108 Scott Hall, 1090 Carmack Road, Columbus, OH 43210. (email: bromwich@polarmet1.mps.ohio-state.edu)

(Received October 14, 1993; revised April 29, 1994; accepted July 5, 1994) 